\title{
ETNOMARKETING:
}

\section{antropologia, cultura e consumo}

Pedro Jaime Júnior

Mestre em Antropologia Social pela Unicamp,

Pesquisador do Centro Educacional de Tecnologia em Administração (Cetead)

e Professor da Universidade Salvador.

E-mail: pedrojaime@uol.com.br

\section{RESUMO}

Neste artigo, pretende-se, inicialmente, ressaltar a presença de dimensões culturais e simbólicas no universo do consumo e evidenciar o recurso ao aporte antropológico na gestão de marketing, mediante a apresentação de alguns casos extraídos da literatura de difusão sobre o universo empresarial. Em seguida, com base no método

biográfico, são descritas as trajetórias profissionais de dois antropólogos que têm empreendido trabalhos práticos situados no campo da Administração Mercadológica. O propósito final é contribuir para a discussão sobre a fronteira interdisciplinar que envolve a Antropologia do Consumo e a Mercadologia.

\section{ABSTRACT}

At first the article attempts to point the cultural and symbolic aspects of the consumption and the use of an anthropological approach on the marketing management. Therefore, the text focuses on real situations that

have been occured in the business world. Afterwards, using the biographic method, it describes the professional trajectories of two anthropologists who have been acting in the marketing field for many years. Furthermore, there is a goal to contribute to discussions about the interdisciplinary boundary that envolves Anthropology of Consumption and Marketing Management.

\section{PALAVRAS-CHAVE}

Marketing, comportamento do consumidor, antropologia, antropologia do consumo, cultura. 


\section{INTRODUÇÃO}

O atual contexto sócio-histórico, já qualificado por muitos como pós-moderno, caracteriza-se por uma reestruturação na organização da atividade econômica. Entre outros aspectos, nota-se uma passagem do consumo de massa para uma cultura do consumo marcada pela existência de diversos estilos de vida que refletem a explosão de microidentidades ${ }^{1}$. Essa mudança obriga as empresas a pensarem outras estratégias de segmentação de mercado, para além das tradicionais classificações por região geográfica e renda.

Fatos que evidenciam essa alteração podem ser percebidos na literatura brasileira de difusão sobre o mundo dos negócios. Esta tem enfatizado, nos últimos anos, a presença de dimensões simbólicas informando o comportamento do consumidor. Diversas reportagens de publicações como Exame e Gazeta Mercantil apresentam casos que apontam a necessidade de as empresas atentarem para a variável cultural na elaboração de suas estratégias de marketing, sob pena de incorrerem em grandes fracassos mercadológicos.

À medida que as dimensões culturais e simbólicas foram ganhando importância cada vez maior na explicação do comportamento do consumidor, os departamentos de marketing das empresas, os institutos de pesquisa de mercado e as agências de publicidade passaram a recorrer ao aporte antropológico, recrutando muitas vezes profissionais com formação em Antropologia - disciplina voltada à análise dos fenômenos socioculturais.

Neste artigo, pretende-se ressaltar a presença de dimensões culturais e simbólicas no universo do consumo e evidenciar o recurso ao aporte antropológico na gestão de marketing, mediante a apresentação de algumas situações concretas extraídas da literatura de difusão sobre o universo empresarial. Em seguida, com base no método biográfico (Bertaux, 1980; Becker, 1999), descrevem-se as trajetórias profissionais de dois antropólogos que têm empreendido trabalhos práticos no campo da Administração Mercadológica. Antes, porém, será apresentada, na próxima seção, uma breve discussão sobre a disciplina antropológica e um dos seus subcampos: a Antropologia do Consumo. O propósito final é contribuir para a discussão sobre a fronteira interdisciplinar que envolve a Antropologia do Consumo e a Mercadologia.

\section{A DISCIPLINA ANTROPOLÓGICA E O SUBCAMPO DA ANTROPOLOGIA DO CONSUMO}

Neste texto, parte-se do pressuposto de que o leitor já possui alguns conhecimentos sobre a Antropologia. Portanto, não será desenvolvida uma apresentação extensa dessa disciplina. Antes de tratar da Antropologia do Consumo, serão apresentadas algumas bases gerais sobre as quais se sustenta a própria Antropologia, destacando-se pontos de concordância entre os antropólogos, independente de seus pertencimentos a diferentes correntes teóricas.

A Antropologia construiu-se, historicamente, como o estudo do outro, entendido como outra sociedade, outra cultura, outro grupo social, enfim, aquele que se comporta de forma diferente de mim. Em outras palavras, a Antropologia configurou-se como uma tentativa de compreender a diversidade cultural, em um encontro radical com a alteridade.

\section{A ANTROPOLOGIA SE CONSTRUIU}

\section{HISTORICAMENTE COMO ESTUDO DO OUTRO, ENTENDIDO COMO}

\section{OUTRA SOCIEDADE, OUTRA CULTURA, OUTRO GRUPO SOCIAL.}

Todavia, questionando-se os resultados extraídos desse encontro com a alteridade, nota-se que há discordâncias. A descoberta de universais humanos, a descrição de uma cultura em sua totalidade e a experiência fragmentária de diálogo intercultural seriam algumas das respostas dadas pelos antropólogos. De toda forma, a imagem da Antropologia como um encontro com o outro parece representar um consenso para a comunidade antropológica.

Talvez também possa denotar uma concordância a defesa da etnografia como o método de pesquisa por excelência da Antropologia. No final do século XIX, quando ela estava-se institucionalizando como campo científico, os trabalhos de investigação eram realizados pelo que se convencionou chamar de "antropólogos de gabinete". Estes não chegavam a conhecer face a face os membros dos grupos sociais estudados pela disciplina. Para construir uma explicação sobre os "estranhos" comportamentos dos povos "primitivos", eles utilizavam dados recolhidos por viajantes, missionários e funcionários do governo colonial².

Essa situação modificou-se no início do século XX, e costumam-se atribuir à Bronislaw Malinowski, um polonês naturalizado britânico, os créditos pelo surgimento do método etnográfico, que caracterizou a moderna Antropologia Social e que marca a disciplina até hoje. Malinowski julgava que o recurso a missionários, administradores coloniais ou viajantes derivava em uma série de dados distorcidos, uma vez que a percepção desses indivíduos não estava imune ao preconceito.

O próprio antropólogo deveria ir a campo. Seria indispensável o recurso ao "olhar antropológico", aquele supostamente desprovido de preconceito, capaz de relativizar, escapando da postura etnocêntrica, isto é, capaz de entender a outra sociedade a partir das razões que seus próprios membros constroem para justificar seus 
comportamentos. Durante a segunda década do século XX, Malinowski passou uma longa temporada entre os nativos das ilhas Trobriand, na Oceania, desenvolvendo um estudo etnográfico que resultou no livro Argonautas do Pacífico Ocidental, um clássico da Antropologia (Malinowski, 1984).

Isso não significa, evidentemente, que todos os antropólogos sejam etnógrafos. Alguns profissionais dessa disciplina parecem mais afeitos a contribuir com o avanço da teoria antropológica sem realizar o fieldwork, e não seria equivocado relatar que Marcel Mauss, certamente um dos mais célebres antropólogos do século XX, nunca desenvolveu trabalhos de terreno, ainda que tenha escrito um Manual de etnografia (Mauss, 1993). De toda forma, esses antropólogos atribuem um valor central aos dados etnográficos, isto é, eles partem das etnografias escritas por outros antropólogos. Esse foi o caso de Mauss no também clássico Essai sur le don, quando partiu dos trabalhos etnográficos de, dentre outros, Franz Boas e Malinowski para construir uma teoria sobre a troca nas sociedades "primitivas" (Mauss, 1974). Sem cair num raciocínio excludente, a Antropologia fez uma síntese, assumindo a etnografia como sua marca distintiva no âmbito das Ciências Sociais e, conseqüentemente, valorizando o trabalho de campo etnográfico na construção de sua teoria.

Enfim, mesmo duvidando das possibilidades de estabelecer consensos em questões relacionadas à Antropo$\operatorname{logia}{ }^{3}$, se se quiser arriscar uma definição sintética para a disciplina, pode-se apontar a compreensão do outro possibilitada pela prática etnográfica. Em outras palavras, a Antropologia seria o encontro etnográfico com o outro.

Vale lembrar que, originariamente, esse "outro", objeto dos estudos antropológicos, eram as sociedades tradicionais. Assim, a Antropologia ficou conhecida, durante muito tempo, como a ciência das sociedades "primitivas". Porém, ao longo da sua história, ela foi redefinida. Essa redefinição pode ser resumida numa ressalva feita pelo filósofo francês Maurice MerleauPonty (1980). Ele afirmava que a Antropologia não é uma especialidade definida por um objeto particular as sociedades "primitivas" -, mas uma maneira de pensar caracterizada pelo estranhamento que se impõe quando o objeto é o outro. Trata-se de definir a Antropologia não em relação a um objeto empírico, mas a um objeto intelectual (Augé, 1994, 1999).

O antropólogo francês Claude Lévi-Strauss analisou muito bem essa transformação. Em artigo publicado nos anos 60, denominado A crise moderna da Antropologia, Lévi-Strauss (1962) questionou a possibilidade de a Antropologia tornar-se uma ciência sem objeto, fadada, portanto, a desaparecer. Essa preocupação estava ancorada na evidência do genocídio cultural que o Ocidente promoveu com diversas sociedades tribais e na constatação de que a maior parte daquelas que subsistiam estavam-se transformando em sociedades muito parecidas com as metrópoles européias: organizavam-se politicamente a partir de um Estado-Nação, estavam em vias de industrialização, etc.

Não se trata aqui de retomar o raciocínio do mestre francês em sua íntegra, apenas frisar a constatação que ele faz ao finalizar o artigo: "ora, enquanto as maneiras de ser e de agir de certos homens forem problemas para outros homens, haverá lugar para uma reflexão sobre essas diferenças, que, de forma sempre renovada, continuará a ser o domínio da Antropologia" (Lévi-Strauss, 1962). Cerca de 20 anos mais tarde, um outro antropólogo, o norte-americano Clifford Geertz (1983), vaticinou: "agora somos todos nativos."

Assim, dentro do vasto espectro do que se convencionou chamar de Antropologia das Sociedades Complexas ${ }^{4}$, muitos novos temas foram-se incorporando à disciplina, dentre eles, a Antropologia do Consumo, sobre a qual serão tecidos breves comentários.

O propósito aqui não é reconstruir a genealogia desse subcampo dos estudos antropológicos. Ao leitor interessado, sugere-se seguir as pistas deixadas pelos franceses Philippe Laburthe-Tolra e Jean-Pierre Warnier. No texto Produção social e consumo de objetos (1997), esses autores consideram a publicação do trabalho $A$ dimensão oculta, de Edward T. Hall, o marco fundador da Antropologia do Consumo. Segundo eles, os trabalhos de Hall inauguram uma abordagem antropológica dos domínios do consumo relativos ao espaço: a arquitetura, o mobiliário, a decoração interior, as cores, a iluminação, a climatização, as vestimentas, os transportes coletivos, os lugares de trabalho, os espaços de lazer, as vias públicas, etc. No artigo, Laburthe-Tolra e Warnier resenham também diversos outros textos que consideram inseridos no campo da Antropologia do Consumo, dentre os quais destaca-se o já clássico trabalho de Douglas e Isherwood (1978). Além disso, apresentam os contornos desse subcampo da disciplina antropológica, retomando suas raízes mais remotas, nos trabalhos de antropólogos clássicos como Marcel Mauss e André Leroi-Gourhan, e apontando os seus limites porosos com a Sociologia, seja também em sua tradição clássica - por meio das obras deixadas por Marx, Weber, Simmel, Veblen e Nobert Elias -, seja na produção contemporânea de autores como Pierre Bourdieu e Jean Baudrillard.

O trabalho dos antropólogos franceses representa um excelente mapeamento introdutório. Não se pode, contudo, deixar de destacar uma ausência importante no texto. Trata-se da referência ao antropólogo norte-americano Marshall Sahlins, cujas idéias parecem oportunas para compreenderem-se as evidências empíricas da presença de dimensões simbólicas informando o comportamento do consumidor e as trajetórias profissionais de antropólogos no campo da Administração Mercadológica, apresentadas nas próximas seções deste artigo.

$\mathrm{Na}$ sua interpretação da sociedade capitalista ocidental, Sahlins (1979) demonstrou que essa sociedade, que 
se auto-representa como regida exclusivamente pela racionalidade econômica, sendo desprovida de dimensões culturais e do simbólico, na verdade, é, ela mesma, uma forma específica de ordem cultural. Para ele, o sistema de representações simbólicas informa a própria organização da atividade econômica na sociedade capitalista, ou seja, as esferas da produção e do consumo são espaços privilegiados de produção simbólica nesta sociedade. Assim, sua especificidade não reside no fato de o sistema econômico escapar à determinação simbólica, mas antes na constatação de que nela o simbolismo econômico é estruturalmente determinante.

Partindo dessa interpretação da sociedade capitalista, o autor entende que o significado social de um objeto, o que o torna útil a certa categoria de pessoas, é menos visível por suas propriedades físicas do que pelo valor que ele assume na troca. A utilidade, destaca Sahlins, não é uma qualidade intrínseca do objeto, mas um significado construído pelos sujeitos. Neste sentido, nenhum objeto é ou tem movimento na sociedade humana, exceto pela significação que os homens lhe atribuem. Suas análises dos sistemas alimentar e de vestuário nos EUA, lastreadas na abordagem estruturalista, são bastante interessantes.

Para ele, o papel do antropólogo é descobrir a ordem cultural escondida na sociedade; ele estabelece, então, uma analogia entre o trabalho desse profissional e aquele desempenhado pelos pesquisadores de mercado e agentes publicitários. Estes últimos procuram responder às constantes reformulações das relações simbólicas dentro da vida social, a fim de tornar um "produto-símbolo" um sucesso mercantil $1^{5}$. Pode-se resumir sua análise do simbolismo econômico nas sociedades capitalistas pelo seguinte argumento: o fenômeno do consumo não pode ser compreendido levando-se em consideração apenas variáveis de natureza econômica, isto é, as mudanças na estrutura de produção e seus impactos em termos de distribuição de renda. Devese atentar também para variáveis socioculturais.

A seguir, apresentam-se exemplos empíricos que corroboram a posição de Sahlins, uma vez que demonstram o papel que joga a dimensão simbólica no universo do consumo.

\section{DIMENSÕES SIMBÓLICAS DO CONSUMO E RECURSO AO APORTE ANTROPOLÓGICO NA GESTÃO DE MARKETING: ALGUNS EXEMPLOS EMPÍRICOS}

A revista Exame de 10 de fevereiro de 1999 traz uma matéria que trata da nova linha de produtos da Embeleze, empresa de cosméticos situada no Rio de Janeiro, lançada para o segmento de mercado evangélico. De acordo com o texto, tal linha de produtos, denominada "Beleza Cristã", procura passar uma imagem mais próxima dos valores dos evangélicos. A adaptação da estratégia de marketing da empresa ao universo simbólico dos consumidores pode ser percebida logo de início pelo nome dos artigos: "Colônia Cordeirinho" e "Condicionador Promessa". A composição do produto não conta com ingredientes de origem animal como o colágeno, uma vez que, segundo a empresa, os evangélicos não são favoráveis ao sacrifício de animais para fins industriais. É dada atenção também à embalagem e à publicidade, que não contam com modelos apresentando um visual provocante, em vista da reticência dos membros desse grupo a apelos de ordem sexual. Ao contrário, os rótulos dos produtos trazem versículos bíblicos como: "lembra-te do teu criador nos dias de tua mocidade". A eficácia simbólica dessas estratégias pode ser percebida nos resultados financeiros da empresa. Competindo com multinacionais como a Revlon e a L'Oréal, a Embeleze, que também possui produtos voltados para os afro-brasileiros, passou de um faturamento de 36 milhões de reais em 1994 para 85 milhões de reais em 1998.

\section{O FENÔMENO DO CONSUMO NÃO}

\section{PODE SER ENTENDIDO LEVANDO-SE}

\section{EM CONSIDERAÇÃO APENAS}

\section{VARIÁVEIS DE NATUREZA ECONÔMICA.}

Em 25 de fevereiro de 1998, a mesma revista havia publicado uma reportagem denominada Prova de obstáculos. $\mathrm{O}$ artigo trazia a seguinte chamada: "Empresas brasileiras aprendem a competir ao superar hábitos e exigências diferentes no Mercosul". Dentre os exemplos fornecidos, o caso da inserção da Brahma no Mercosul chama a atenção. A empresa gastou 150 milhões de dólares para produzir a cerveja em garrafas de 1 litro. Pesquisas de mercado teriam apontado que o consumidor argentino consome cerveja com os amigos, mas no espaço privado, isto é, em casa, ao passo que o consumidor brasileiro prefere o consumo da cerveja no espaço público, ou seja, na rua $^{6}$. A companhia optou, então, por alterar a embalagem. Com isso, o consumidor argentino passou a levar mais líquido para casa em menos recipiente. No que tange ao mercado de refrigerantes, a matéria informava também que, somente na Argentina, a Brahma comercializa um produto à base de pomelo, fruta parecida com a laranja.

Na revista Veja de 30 de junho de 1999, consta o artigo Ao gosto do freguês, com o seguinte subtítulo: "Empresas adaptam as fórmulas de seus produtos para conquistar o emergente mercado nordestino". Segundo a reportagem, nos últimos dois anos, a produção de riquezas no Nordeste havia aumentado dez vezes mais que a média nacional. Com isso, a região ganhou a atenção dos fabricantes de produtos de consumo. $\mathrm{O}$ ponto central do texto pode ser resumido da seguinte forma: este é um excelente mercado emergente para as empresas. Todavia, suas parti- 
cularidades devem ser observadas. Não se pode apenas colocar no Nordeste produtos que fazem sucesso em outras regiões, devem-se adaptá-los ao gosto e aos costumes locais. Os exemplos descritos são curiosos e ilustrativos. A margarina "Delícia", da Unilever, recebeu mais sal e mais corante amarelo para parecer com a manteiga de garrafa, tradicional no Nordeste. A Pizza Hut, uma das maiores cadeias americanas de fast-food, alterou seu cardápiopadrão internacional para incorporar na Bahia e em Pernambuco a "pizza baiana", com temperos picantes que a aproximam da apimentada culinária regional. A Kibon produz exclusivamente na região sorvetes fabricados com frutas típicas como cajá, mangaba, graviola e acerola. Tais sorvetes são os mais vendidos pela empresa no Nordeste.

Os exemplos poderiam multiplicar-se. Assim como evangélicos, argentinos e nordestinos, podem-se apontar diversos outros casos de produtos criados ou adaptados atentando-se para identidades culturais construídas a partir de elementos religiosos, nacionais, regionais ou quaisquer outras formas de identificação que se refletem nos comportamentos de consumo dos seus membros. A esses grupos os antropólogos costumam denominar "comunidades simbólicas". Na linguagem do marketing, eles são considerados "segmentos ou nichos de mercado".

A observação desses exemplos leva à seguinte constatação: se, por um lado, profissionais de marketing e publicitários jogam cada vez mais com as dimensões simbólicas do consumo em suas práticas profissionais, por outro lado, eles não trabalham com as elaborações mais recentes de cultura e identidade da Antropologia. Há muito de essencialismo na visão de cultura expressa nos exemplos acima, a construção das identidades culturais parece ser atribuída a núcleos centrais supostamente irredutíveis. O que é ser evangélico? Possuir cabelos longos, vestir saia comprida e andar com a bíblia debaixo do braço? O que é ser nordestino? Comer carne-de-sol com manteiga de garrafa? O que é ser baiano? Comer acarajé quente, isto é, com pimenta? Não se pretende tratar dessas questões aqui, elas não são a motivação deste artigo. Destaca-se, todavia, que o jogo com as identidades culturais expresso nas estratégias mercadológicas descritas parece estar excessivamente preso ao estereótipo.

O que interessa reter desses casos é que demonstram a presença de dimensões culturais e simbólicas informando o comportamento do consumidor. Pode-se, então, perguntar se, conseqüentemente, houve uma ampliação do recurso ao aporte antropológico na gestão de marketing. Quanto a esse aspecto, nos últimos anos, a literatura de difusão sobre o mundo dos negócios também é rica em exemplos.

A busca pelo aporte antropológico tem valorizado bastante o método de pesquisa característico da Antropologia: a etnografia, à qual já fizemos alusão na seção precedente. A julgar pelas informações apresentadas na literatura, a utilização do método etnográfico na gestão de marketing não constitui um delírio de executivos ex- cêntricos. As empresas têm obtido resultados concretos com esse recurso. A revista Exame de 10 de fevereiro de 1999 traz um artigo que aborda, explicitamente, a utilização do método etnográfico por algumas empresas. A matéria intitulada Tire o traseiro da cadeira expõe exemplos bem ilustrativos.

$\mathrm{Na}$ Gatorade do Brasil, os funcionários foram estimulados a visitar academias de ginástica para observar e conversar com os consumidores. Durante uma dessas visitas de campo, surgiu uma idéia inovadora, ainda que pareça demasiado óbvia. Descobriu-se que os consumidores só tomavam a bebida depois que retornavam para casa, uma vez que não a levavam para a academia com medo que a garrafa de vidro se quebrasse nem consumiam na cantina por causa do preço elevado. Essa informação, obtida no trabalho de campo, foi a gênese do lançamento do Gatorade em garrafa plástica.

A Black \& Decker passava por maus momentos no segmento "faça você mesmo", perdendo espaço no mercado para concorrentes como a Sears. A empresa decidiu, então, estudar em profundidade os hábitos de 50 consumidores, com o propósito de desvendar por que eles preferiam algumas ferramentas em detrimento de outras. Com isso, a empresa descobriu que seus clientes queriam potentes furadeiras sem fio e serras circulares que não levantassem poeira. A Black \& Decker redesenhou sua linha de produtos e, como resultado, retomou a liderança do mercado.

O jornal Gazeta Mercantil de 18 de março de 1992 também apresenta uma matéria com exemplos ilustrativos. Traduzida da Advertising Age e denominada Antropólogos na Madison Avenue, a reportagem descreve experiências de recurso à pesquisa etnográfica com o objetivo de levantar subsídios para orientar ou reorientar o plano de marketing das empresas. Dentre os diversos casos apresentados no texto está o dos serviços de correio na zona rural e o da General Wills, multinacional fabricante de biscoitos.

Sobre os correios, os antropólogos descobriram que, em áreas rurais, eles são vistos como "um contato com a sociedade, um antídoto para a solidão". Isso redirecionou os anúncios veiculados na mídia eletrônica, que passaram a apresentar o carteiro como um indivíduo comum, enfatizando a dimensão humana dos serviços postais. "Nós entregamos para você" passou a ser o slogan da campanha.

Quanto à General Wills, a matéria aponta o seguinte: mães entrevistadas na pesquisa de marketing afirmaram que a decisão de compra da marca resultava da sua integridade. A pesquisa etnográfica, contudo, revelou que o comportamento de compra era bem diferente. Uma criança pedia para comprar biscoitos e, para a mãe, a marca era quase irrelevante. A vice-presidente associada e diretora de pesquisa e planejamento estratégico da DDB Needham, agência que trabalhava a conta da General Wills, ressaltou que o dado que a pesquisa tradicional fornecia dizia respeito a uma motivação de categoria, ou seja, apontava o que incentivou o consumidor a comprar um produto, mas não uma marca específica. 
Quanto à marca, na maioria das vezes, eram as crianças que definiam a compra.

De todos os exemplos encontrados na literatura de difusão, um chama bastante a atenção. Transcreve-se abaixo a passagem da reportagem publicada na Exame de 10 de fevereiro de 1999, dada a eloqüência do caso referente ao recurso ao aporte antropológico nas práticas de marketing da Gessy Lever:

"Gerentes engravatados da Gessy Lever sobem o morro para entrevistar ao vivo e em cores clientes até então reduzidos a percentagens em impessoais relatórios de pesquisa. (...) Travestidos de garçons ou de telefonistas, os administradores da cadeia Westin de hotéis atendem hóspedes. Ufa! Que canseira. Nada a ver com os bons tempos em que, para desenvolver e lançar novos produtos (ou aperfeiçoar outros já existentes), bastava identificar o público-alvo, fixar o preço e aprovar a campanha de propaganda. Tudo isso sem abandonar o conforto e a privacidade de um escritório refrigerado (...) Isso é passado. Pelo menos nas empresas que hoje melhor se aplicam na prática de entender a cadeia de valores considerados importantes pelos clientes na avaliação de produtos e serviços (...) Existem companhias que levam ao extremo a preocupação de fazer com que seus executivos saiam a campo para investigar as necessidades dos consumidores. No Brasil, o principal expoente dessa corrente é a filial da anglo-holandesa Unilever (...) Essas práticas começaram a ser adotadas há cerca de cinco anos, quando a Gessy Lever transformou seus gerentes em aprendizes de antropólogos. Com gravadores a tiracolo, eles passaram a viajar pelo Brasil para conhecer como vivem e se expressam os consumidores de baixa renda. Por trás do programa havia a intenção de desenvolver o mercado de produtos para essa faixa da população. Como o público-alvo da Gessy Lever sempre foi a classe média, aquele era um universo pouco conhecido (...) As grandes companhias finalmente descobriram que seus gerentes e diretores estavam muito distantes do consumidor."

Do que foi exposto até aqui, pode-se questionar a respeito da natureza dessas pesquisas realizadas, seja por antropólogos, seja por pesquisadores de mercado. Tratase, realmente, de exemplos de utilização do método etnográfico? A centralidade da prática etnográfica na produção do conhecimento antropológico leva a uma resposta negativa a essa questão. Fazer etnografia implica colocar em diálogo as categorias nativas com os conceitos antropológicos. Por essa razão, a etnografia tem sido apontada como uma fonte de renovação teórica para a Antropologia (Geertz, 1983; Peirano, 1995). Todavia, a partir dos anos 80, quando a Antropologia ganhou maior visibilidade tanto no interior quanto no exterior das Ciências Sociais (Durham, 1986), a "perspectiva antropológica" e o "olhar antropológico" passaram a ser recursos reivindicados por diversas disciplinas, do campo da Saúde à área da Educação, passando pela Administração, na con- dução de pesquisas. Esse empréstimo coloca difíceis questões, que não se pretende tratar aqui.

De toda forma, parece inútil que, em um cenário de revisões, renegociações e redemarcações das fronteiras disciplinares, a Antropologia apresente-se no papel de guardiã da etnografia. Levando-se em conta os devidos rigores, o método etnográfico pode ser bem utilizado em outros campos do saber, permitindo a outras disciplinas o confronto dos seus próprios conceitos com contextos empíricos específicos. Ainda assim, não parece correto denominar pesquisa etnográfica práticas que, na verdade, são trabalho de campo, observação, mas não etnografia. Apesar de toda a complexidade envolvida nessa questão, utilizam-se aqui os termos "pesquisa etnográfica" e "método etnográfico" com o objetivo de chamar a atenção para o fato de que a etnografia é acionada como um importante "capital simbólico" (Thompson, 1995) pelos antropólogos que vêm construindo uma inserção no mundo do marketing.

\section{A etNografia DE GRUPOS DE}

\section{CONSUMIDORES BUSCA MAPEAR AS}

\section{MOTIVAÇÕES DE COMPRA A PARTIR}

\section{DA TRÍADE INDIVÍDUOS-GRUPOS}

\section{DE REFERÊNCIA-PRODUTOS.}

Tendo ressaltado o substrato cultural e simbólico do consumo e o recurso ao aporte antropológico no âmbito do marketing, serão discutidas, a seguir, com base no método biográfico (Bertaux, 1980; Becker, 1999), as trajetórias profissionais de dois antropólogos no campo da Administração Mercadológica? .

O método biográfico, também denominado de "história de vida", ficou notabilizado entre as metodologias qualitativas desde a sua extensa utilização pela Escola de Chicago em estudos sobre imigrantes, jovens delinqüentes, prostitutas e outros grupos de desviantes. Segundo Becker, tal método atribui grande importância às interpretações que as pessoas fazem de sua própria experiência, representando, assim, importante via de acesso ao vivido subjetivo. Dada a sua riqueza, o método biográfico aplica-se a propósitos como a verificação de pressuposições (Becker, 1999) e a construção de hipóteses (Bertaux, 1980). Assim, ele parece bem adequado ao interesse deste estudo, que pretende verificar o pressuposto de que tem ocorrido um recurso ao aporte antropológico na Administração Mercadológica.

Vale ressaltar, entretanto, uma limitação na utilização desse método na presente pesquisa. $\mathrm{O}$ interesse esteve voltado apenas para a biografia ocupacional dos infor- 
mantes, ao passo que Bertaux (1980) destaca que, com a separação domicílio-trabalho promovida pelo advento da sociedade capitalista, muitas pessoas passaram a viver vidas paralelas: uma no trabalho, outra na família, uma terceira correspondente a algum projeto pessoal. De toda forma, esse mesmo autor ressalta que nem todas as pesquisas que fazem uso desse método precisam obrigatoriamente abranger a totalidade da existência dos sujeitos sociais. É preciso destacar ainda que as histórias de vida profissional apresentadas aqui foram recolhidas mediante entrevistas semi-estruturadas, ou seja, entrevistas aplicadas a partir de um pequeno número de perguntas abertas (Thiollent, 1981).

\section{TRAJETÓRIAS PROFISSIONAIS DE ANTROPÓLOGOS NO CAMPO DA ADMINISTRAÇÃO MERCADOLÓGICA}

\section{Antropologia e consultoria em marketing: a trajetória do profissional A}

Vindo de graduação e de mestrado em Comunicação - ocasião em que analisou a representação social da profissão de publicitário -, o profissional A ingressou, inicialmente, no mestrado e, em seguida, no doutorado em Antropologia Social de uma conceituada instituição do eixo Rio-São Paulo. Suas pesquisas em Antropologia possuem uma solução de continuidade com sua formação na área de Comunicação. Publicidade, comunicação de massa e consumo foram temáticas privilegiadas, relacionadas com a questão cultural.

Até a defesa da dissertação de mestrado em Antropologia, ele não havia vislumbrado a possibilidade de aplicar os conhecimentos produzidos na trajetória acadêmica em trabalhos de consultoria. Entretanto, quando cursava o doutorado, recebeu um convite para ministrar um pequeno curso em um programa de pós-graduação em Administração do Sudeste brasileiro.

Os professores de marketing do programa tiveram acesso à sua dissertação de mestrado, que fora transformada em livro, e entenderam que havia possibilidades de convertê-la numa linha de pesquisa. Assim, de um pequeno curso inicial, ele foi convidado, após a conclusão do doutoramento, também transformado em livro, para atuar como professor associado, ministrando duas cadeiras: Antropologia Social, como disciplina obrigatória para mestrandos e doutorandos, e Antropologia do Consumo, como seminário especial para o doutorado.

No decorrer do seu trabalho nessa instituição, o profissional A começou a perceber a utilidade prática da interpretação antropológica na consultoria em Administração Mercadológica. Para ele, a Antropologia pode prestar excelente auxílio às empresas na formulação dos seus planos de marketing: "A Antropologia pode dar uma contribuição enorme ao que se denomina em marketing de comportamento do consumidor. Entender mais a fundo porque as pessoas compram, de que forma consomem, como é que os grupos se classificam vis-à-vis outros grupos a partir do uso de determinados objetos, esses são espaços que podem ser ocupados pelos antropólogos."

O profissional A vem atuando como consultor de empresas nessa fronteira entre a Antropologia do Consumo e a gestão de marketing. Ele vem desenvolvendo trabalhos em basicamente três direções.

A primeira delas refere-se à orientação para elaboração do planejamento de marketing das empresas e definição de ações estratégicas. As metodologias de elaboração do planejamento empresarial tradicionalmente cruzam, numa estrutura matricial, uma análise do ambiente externo - em termos de ameaças e oportunidades - com um exame do ambiente interno - que procura identificar os pontos fortes e os pontos fracos da organização. As informações resultantes desse cruzamento embasam a definição das ações que serão desenvolvidas na condução dos negócios. Para auxiliar na análise do ambiente externo, geralmente, as empresas contratam economistas, que empreendem os chamados "estudos de cenário".

O profissional A argumenta que o recurso ao saber antropológico é importante tanto na análise externa quanto na interna. No que tange à análise externa, a leitura da cultura brasileira e a percepção das diferenças culturais em um mundo globalizado podem ajudar a empresa a antecipar-se às ameaças e/ou oportunidades ambientais. Seguindo a linha de Sahlins (1979), ressaltou que as ameaças e oportunidades não dizem respeito apenas à dimensão econômica. Assim, a análise sociocultural do ambiente externo também deve direcionar a formulação do planejamento de marketing. Quanto à análise interna, a leitura das dimensões culturais da empresa representa importante contribuição à análise organizacional. O profissional A já foi contratado por um grande banco brasileiro para fazer um estudo da sua cultura organizacional.

A "etnografia de grupos de consumidores" foi outra prática apontada pelo profissional A. Partindo também da abordagem desenvolvida por Sahlins $(1979)^{8}$, para quem o consumo atua nas sociedades capitalistas como uma espécie de "operador totêmico" capaz de classificar os indivíduos em grupos, ele destacou que a "etnografia de grupos de consumidores" busca mapear as motivações de compra a partir da tríade indivíduos-grupos de referência-produtos. O profissional $\mathrm{A}$ informou que já foi contratado por grandes empresas para realizar pesquisas qualitativas, etnográficas, com grupos específicos de consumidores (donas de casa, representantes das camadas médias da sociedade, etc.). O seu papel era o de interpretar os significados que os membros desses grupos atribuem a determinados produtos e a seus concorrentes e desvendar a forma como esses produtos são utilizados.

Há, ainda, uma terceira via de atuação do profissional A: o apoio às empresas na relação com as agências de 
publicidade. Seu trabalho consiste em propor estratégias de posicionamento dos produtos no mercado em virtude dos valores e da visão de mundo específicos do públicoalvo. Trata-se de identificar features a serem fixadas à imagem dos produtos nas campanhas de comunicação.

Com sólida formação em Antropologia, o profissional A conseguiu articular sua inserção na consultoria em marketing. Todavia, a atividade de consultoria é algo complementar na sua prática profissional. Ele afirma que a pesquisa acadêmica e a docência são suas ocupações principais. Tal não é o caso da personagem cuja biografia ocupacional apresenta-se a seguir. Sua trajetória foi construída privilegiando mais as atividades práticas do que as acadêmicas, e hoje ela atua full-time como profissional de marketing.

Uma antropóloga na pesquisa de marketing: a trajetória da profissional $\mathrm{B}$

A profissional B concluiu a graduação em Ciências Sociais e o mestrado em Antropologia Social em instituições renomadas do Sudeste brasileiro. A aproximação com o universo do marketing iniciou-se na década de 70, com a decisão de procurar uma empresa que financiasse os trabalhos de pesquisa da sua dissertação de mestrado, cujo tema era a publicidade. A empresa-parceira terminou contratando-a, após a defesa da dissertação, para desenvolver dois projetos: o primeiro na área de comunicação social, investigando a imagem da empresa perante a opinião pública, e o segundo no campo do endomarketing, utilizando técnicas de dinâmica de grupo no treinamento de pessoal para o lançamento de novos produtos.

Ao desligar-se dessa companhia, ela assumiu, por circunstâncias particulares, a administração geral de uma empresa de médio porte de seu grupo familiar. A experiência durou cerca de dois anos, sendo fundamental, segundo ela, para reforçar o seu interesse pela atividade gerencial.

Posteriormente, a profissional B passou a trabalhar em um instituto que realizava pesquisas de marketing para diversas empresas. Devido à rede de relações com "homens de negócios" construída nesse período, foi contratada para atuar no departamento de marketing de uma empresa multinacional. A partir daí, teve sucessivas experiências de Administração Mercadológica em empresas de diferentes setores da economia, ocasião em que se encontrava numa situação inversa àquela vivenciada no instituto: passara a contratar pesquisas de marketing.

Durante esse tempo, complementou sua formação acadêmica e profissional com uma pós-graduação em marketing. Dessa forma, pôde incorporar à sensibilidade que a Antropologia lhe fornecera para o trabalho no campo da gestão mercadológica outros conhecimentos que não haviam sido adquiridos nos estudos de Ciências Sociais, a exemplo de distribuição física dos produtos, administração de vendas e política e formação de preços. A aprendizagem dessas habilidades não era motivada apenas por uma razão prática. A profissional B ressaltou que a familiaridade com a linguagem própria desse métier, o domínio da terminologia consagrada no universo do marketing, foi um importante "capital cultural" (Bourdieu, 1987) adquirido com a pós-graduação. Ao findar o curso, ela foi contratada para lecionar na mesma instituição.

Sua experiência de trabalho nas duas pontas do processo de pesquisa de marketing, como pesquisadora e como contratante, terminou levando-a a abrir sua própria empresa de pesquisa mercadológica. Sua decisão é explicada da seguinte forma: "Eu sabia fazer pesquisa, então comecei a pensar nos elementos que sentia falta nos fornecedores que me entregavam os trabalhos que encomendava. Sentia falta de um aprofundamento maior das análises que eram feitas a partir dos dados levantados. Havia possibilidade de fundamentar de forma mais consistente a observação do comportamento do consumidor. Então achei que esse poderia ser o diferencial do meu produto, da minha pesquisa".

\section{A Gessy LeVer tRAnsformou}

\section{SEUS GERENTES EM APRENDIZES DE}

\section{ANTROPÓLOGOS: ELES VIAJARAM PELO}

\section{BRASIL PARA CONHECER COMO VIVEM}

\section{OS CONSUMIDORES DE BAIXA RENDA.}

A empresa não teve muitas dificuldades para conquistar espaço no mercado, uma vez que ela possuía um "capital de relacionamento" fundamental para alavancar o negócio. Os diversos alunos que passaram pelas disciplinas que ela ministrava no programa de pós-graduação em Administração Mercadológica estavam posicionados em cargos de gerência de marketing ou gerência de produto em grandes empresas.

Uma interpretação apressada da biografia ocupacional da profissional B poderia levar a supor que ela não é mais uma antropóloga ou que fizera uma escolha profissional errada, tendo oportunidade de corrigir o rumo no desdobramento da sua trajetória. As coisas, entretanto, não se passam de maneira tão simples assim. A construção das identidades sociais é um jogo complexo que envolve a "auto-identificação" e a "identificação pelos outros" (Cardoso de Oliveira, 1976; Ruben, 1988, 1992). Embora a profissional reconheça que teve dificuldades no relacionamento com os pares antropólogos em decorrência de sua aproximação com o mundo empresarial, o que a fez se sentir um "caso desviante" na instituição onde cursou o mestrado - ainda que acredite que hoje seus ex-professores e ex-colegas de Antropologia não a consideram uma profissional da área -, ela fez questão de frisar em diversos momentos que se auto-atribui a identidade de antropóloga: "Eu me vejo como antropóloga, no sentido do 
exercício do saber antropológico, mas numa outra instância. Me vejo assim porque depois que você adquire a forma de pensar o mundo da Antropologia, você não consegue viver sem ela (...) As ferramentas que a gente adquire nos cursos de Sociologia e especialmente de Antropologia são muito valiosas para a realização da pesquisa de marketing. Em que sentido? No sentido que a pesquisa de mercado busca descobrir estruturas de raciocínio que embasam processos decisórios que levam as pessoas a adotar determinados produtos e rejeitar outros, a se encantar com mensagens publicitárias (...) Quando estou pesquisando um produto, tenho que ter uma sensibilidade para entender o comportamento do outro, senão acabo colocando o que eu acho, e o que eu acho não é o que o consumidor acha. Então esse distanciamento que sou obrigada a construir reforça minha condição de antropóloga".

A ambigüidade de sua identidade evidencia-se também na percepção que as empresas contratantes têm do seu trabalho. Ao ser perguntada se essas empresas a identificam como antropóloga e se visualizam e valorizam a contribuição que a Antropologia pode oferecer ao campo da Administração Mercadológica, a profissional B respondeu que em alguns casos sim, mas em muitos outros não. Ela acredita que, na maior parte das vezes, o universo empresarial ainda percebe a Antropologia como um campo exótico. Exótico, mas não necessariamente negativo, ao contrário, despertando interesse, suscitando curiosidade. A identificação "Antropóloga" abre seu curriculum, utilizado como carta de apresentação da empresa. Na verdade, ela não tem certeza se as empresas contratantes possuem a consciência de que estão comprando um serviço que agrega conhecimentos de Antropologia. Se omitisse essa informação, talvez não fizesse falta, ressaltou. De toda forma, prefere não tomar essa atitude, por acreditar que a Antropologia, mesmo sendo uma disciplina que "não faz o seu próprio marketing", "não divulga as contribuições que pode oferecer às empresas", vem ganhando, nos últimos anos, maior visibilidade no universo empresarial.

Dois aspectos tornam a experiência da profissional B singular. Em primeiro lugar, o fato de ter conquistado um novo espaço no mercado de trabalho. Não se trata de uma profissional situada no universo acadêmico, prestando serviços eventuais de consultoria em marketing, mas de alguém que se pretende antropóloga prática, tendo montado uma empresa para interagir full-time com o universo empresarial. Em seguida, o seu pioneirismo. Sua trajetória no mundo do marketing iniciou-se ainda na primeira metade dos anos 70. A julgar pelos dados etnográficos levantados durante uma dissertação de mestrado (Jaime Júnior, 1997), ela foi a primeira antropóloga brasileira a tornar-se uma profissional de marketing.

A essas biografias ocupacionais certamente poderiam se juntar outras. De toda forma, as duas experiências descritas parecem comprovar que, motivados pelo importante papel que jogam as dimensões culturais e simbólicas no universo do consumo, os departamentos de marketing das empresas, os institutos de pesquisa de mercado e as agências de publicidade têm recorrido ao aporte antropológico. Os personagens das trajetórias apresentadas neste artigo perceberam esse movimento e, então, orientaram ou reorientaram suas práticas profissionais, aproveitando esse espaço aberto aos antropólogos no mercado de trabalho.

\section{CONSIDERAÇÕES FINAIS}

Pretendeu-se, neste artigo, contribuir para a discussão sobre a fronteira interdisciplinar que envolve a Antropologia do Consumo e a Administração Mercadológica. Para tanto, a estratégia narrativa adotada no texto privilegiou dois aspectos: a) a apresentação de situações concretas que evidenciam o importante papel que jogam as dimensões culturais e simbólicas no universo do consumo e b) a discussão sobre o recurso ao aporte antropológico na gestão de marketing, mediante a apresentação de alguns casos extraídos da literatura de difusão sobre o universo empresarial e a descrição, apoiada no método biográfico, da trajetória profissional de dois antropólogos no campo da Administração Mercadológica.

Acredita-se que os casos e experiências apresentados no texto demonstram que o saber antropológico muito pode contribuir para o avanço da gestão de marketing. Não parece ser por outra razão que um número crescente de empresas venha demandando os serviços desses profissionais. Entretanto, devemos fazer algumas observações a respeito desse recurso ao aporte antropológico. O antropólogo que atua no campo do marketing torna-se um auxiliar da ordem estabelecida? Estariam esses profissionais transformando-se, eles mesmos, naquilo que Sahlins (1979) denominou de "mercenários do símbolo"? Quais as consequiências de tal transformação? O conhecimento antropológico passa a ser uma sofisticada arma para a dominação simbólica do consumidor? Ao construírem estratégias de marketing lastreadas em interpretações antropológicas cada vez mais refinadas, não estariam as empresas ludibriando os indivíduos? Até que ponto estes estão capacitados (ou dispostos) a exercer a cidadania, se contrapondo a tais condutas?

Recomenda-se ao leitor retornar à terceira seção deste texto e reler as considerações sobre a presença de dimensões culturais e simbólicas informando o comportamento do consumidor. No que se refere, por exemplo, ao caso da margarina "Delícia", da Unilever, que recebeu mais sal e mais corante amarelo para parecer-se com a manteiga de garrafa tradicional no Nordeste, cabe perguntar quais são os limites éticos dessa manipulação das dimensões antropológicas do consumo.

Responder a essas questões não é uma tarefa simples. Elas exigem um debate acurado. Portanto, não se pretende discuti-las nem resolvê-las aqui. Talvez devam ser objeto de um outro artigo. De toda sorte, se o risco de o 
conhecimento antropológico ser apropriado de forma espúria no universo do marketing existe, e isso parece inegável, é preferível que os antropólogos corram esse risco e entrem nesse complexo jogo de interesses.

Ao lançarem-se no jogo, eles devem adotar uma estratégia de dupla entrada. Trata-se de conciliar a inserção de antropólogos práticos em organizações empresariais, institutos de pesquisa de mercado e agências de publicidade, com a construção, no ambiente acadêmico, nas universidades, de uma Antropologia do Consumo lastreada numa perspectiva crítica e política. Nessa última direção, a disciplina certamente pode prestar excelente contribuição à compreensão do fenômeno do consumo a partir de uma de suas facetas, muito debatida, mas ainda pouco estudada com um aporte antropológico: o não-consumo. No intuito de provocar o leitor a pensar sobre essa possibilidade, encerra-se este artigo com uma frase do sociólogo português Boaventura de Sousa Santos: "Pior que reduzir o desejo ao consumo é reduzir o consumo ao desejo do consumo" (Santos, 1994, p. 270). $\bigcirc$

\section{NOTAS}

O autor agradece aos professores Maurício Serva, Cloves Oliveira e Francisco Vieira e ao antropólogo Alcides Gussi pelas críticas à primeira versão deste artigo. Contudo, a versão final aqui apresentada é de exclusiva responsabilidade do autor.

1. Para uma discussão sobre a cultura de consumo em um contexto pós-moderno, ver Featherstone (1995).

2. A expressão "povos primitivos" - ou "sociedades primitivas" - é marcada pela perspectiva evolucionista, que concebia os povos tribais como fósseis vivos dos nossos antepassados. Ainda que essa corrente paradigmática esteja superada no âmbito da teoria antropológica contemporânea, tal expressão permaneceu, sendo 0 vocábulo primitivo grafado entre aspas para denotar o seu substrato etnocêntrico.

3. Uma afirmação do antropólogo norte-americano Vicent Crapanzano (1980, p. xiv) parece resumir bem o que estáse tentando ressaltar: "Anthropology should, I believe, lead us to question, not to confirm, our own presumptions."

4. A expressão "sociedades complexas", construída por oposição ao termo "sociedades primitivas", designa as sociedades industriais (ou pós-industriais) que possuem as seguintes características: são formações de larga escala, possuem grande heterogeneidade interna e são marcadas pelo individualismo. As sociedades tribais, por contraste,

\section{REFERÊNCIAS BIBLIOGRÁFICAS}

AUGÉ, Marc. Não lugares: introdução a uma Antropologia da supermodernidade. Campinas: Papirus, 1994.

AUGÉ, Marc. O sentido dos outros. Petrópolis : Vozes, 1999.

BECKER, Howard. Métodos de pesquisa em ciências sociais. São Paulo : Hucitec, 1999. A história de vida e 0 mosaico científico.

BERTAUX, Daniel. L'approche biographique: as validité méthodologique, ses potentialités. Cahiers Internationaux de sociologie. Paris : PUF, 1980. V. 69.

BOURDIEU, Pierre. A economia das trocas simbólicas. São Paulo : Perspectiva, 1987

CARDOSO DE OLIVEIRA, Roberto. Identidade, etnia e estrutura social. São Paulo : Pioneira, 1976.

CRAPANZANO, Vicent. Tuhami, portrait of a Moroccan. Chicago : The University of Chicago Press, 1980.

DAMATTA, Roberto. A casa e a rua. Rio de Janeiro : Guanabara-Koogan, 1991.

DOUGLAS, Mary, ISHERWOOD, Baron. The world of goods: towards an anthropology of consumption. New York : Penguin Books, 1978

DURHAM, Eunice. A pesquisa antropológica com populações urbanas: problemas e perspectivas. In: CARDOSO, Ruth (Org.). A aventura antropológica: teoria e pesquisa. Rio de Janeiro : Paz e Terra, 1986. são compostas por um menor contigente populacional, são mais homogêneas e mais holistas, já que nelas os grupos sociais são mais importantes que os indivíduos. 0 termo problemático, mas não há espaço aqui para desenvolver uma discussão a esse respeito.

5. Vale ressaltar que Sahlins (1979) não vê com bons olhos essa apropriação do conhecimento antropológico pelos profissionais de marketing, tidos por ele como "mercenários do símbolo". É evidente que não se trata apenas de uma idiossincrasia do antropólogo norte-americano. 0 que está por trás de sua posição é a preocupação com a dimensão ética: estariam em jogo os limites da aplicação do sabe antropológico e a responsabilidade social do antropólogo questões que preocupam a disciplina desde a sua origem, no contexto da dominação colonial.

6. Para uma discussão das categorias "público" e "privado" na cultura brasileira, ver os trabalhos do antropólogo Roberto DaMatta, sobretudo seu livro A casa e a rua (DaMatta, 1991)

7. Essas biografias ocupacionais foram recolhidas durante 0 trabalho de campo referente à dissertação de mestrado, na qual, partindo do marco teórico-metodológico da etnografia do saber, foram analisados os encontros entre os saberes da Antropologia e da Administração (Jaime Júnior, 1997).

8. Sahlins está tomando emprestado um termo clássico da Antropologia. Falar das práticas totêmicas é retomar a própria história da disciplina antropológica. Não se tem pretensões nem condiç̃es de refazer essa viagem aqui. Destaca-se porém, o seguinte: Lévi-Strauss $(1986,1989)$ recolocou as bases dos estudos sobre totemismo no âmbito da Antropologia. Para ele, os trabalhos precedentes, inclusive os de Radcliffe-Brown (1989) e os de Freud (1924), cometeram um erro quando tentaram analisar o totemismo a partir da relação dos grupos sociais diretamente com os totens. Bem dentro da sua abordagem estruturalista, ele tentou demonstrar que o centro da discussão deve ser alterado da relação entre o grupo social e o totem para a relação dos grupos sociais entre si, por intermédio dos totens. Do seu ponto de vista, as sociedades "primitivas" empreendem uma operação totêmica quando elegem séries de opostos na natureza por exemplo, animais noturnos por oposição a animais diurnos ou aves por contraste a rastejadores - para realçar as oposições que informam a estrutura social. Nesse sentido, 0 alvo da explicação antropológica seria a correspondência entre uma série de oposições na natureza e uma série de oposições na estrutura da sociedade. Segundo Lévi-Strauss, o totemismo teria desaparecido nas sociedades ocidentais. É justamente aí que entra o ponto de Sahlins. Para ele, o totemismo não desapareceu nas sociedades capitalistas ocidentais. 0 que ocorre é que a operação totêmica é realizada não mais pela mediação de uma série de oposições na natureza, mas buscando-se essas oposiç̃os nos objetos de consumo. Os grupos sociais iriam diferenciar-se uns vis-à-vis os outros por meio das relações que estabelecem com esses objetos.
FEATHERSTONE, Mike. Cultura de consumo e pós modernismo. São Paulo : Studio Nobel, 1995.

FREUD, Sigmund. Totem et tabou. Paris : [s.n.], 1924

GEERTZ, Cliford. Local knowledge: further essays in interpretive anthropology. New York: Basic Books, 1983.

JAIME JÚNIOR, Pedro. Antropologia e administração: encontro de saberes. Uma abordagem etnográfica. Dissertação (Mestrado) - Instituto de Filosofia e Ciências Humanas, Universidade de Campinas, 1997.

LABURTHE-TOLRA, Philippe, WARNIER, Jean-Pierre. Etnologia-Antropologia. Petrópolis : Vozes, 1997. Produção social e consumo de objetos.

LÉVI-STRAUSS, Claude. A crise moderna da Antropologia. Revista de Antropologia, São Paulo, v. 10, p. 19-26, 1962

LÉVI-STRAUSS, Claude. O totemismo hoje. Lisboa : Edições 70, 1986.

LÉVI-STRAUSS, Claude. O pensamento selvagem. Campinas : Papirus, 1989

MALINOWSKI, Bronislaw. Argonautas do pacífico ocidental. São Paulo : Abril Cultural, 1984

MAUSS, Marcel. Sociologia e Antropologia. São Paulo : EPU Edusp, 1974. Ensaio sobre a dádiva.

MAUSS, Marcel. Manual de etnografia. Lisboa : Publicações Don Quixote, 1993.
MERLEAU-PONTY, Maurice. De Mauss à Claude LéviStrauss. In: CHAUI, Marilena (Org.). Textos escolhidos: Maurice Merleau-Ponty. São Paulo : Abril Cultural, 1980.

PEIRANO, Mariza. A favor da etnografia. Rio de Janeiro : Relume-Dumará, 1995.

RADCLIFFE-BROWN, A. R. Estrutura e função nas sociedades primitivas. Lisboa : Edições 70, 1989. A teoria sociológica do totemismo.

RUBEN, Guilhermo. Teoria da identidade: uma crítica. Anuário Antropológico/86. Rio de Janeiro : Tempo Brasileiro, 1988

RUBEN, Guilhermo. Teoria da identidade na Antropologia: um exercício de etnografia do pensamento moderno. In: CORRÊA, Mariza, LARAIA, Roque (Orgs.). Roberto Cardoso de Oliveira: homenagem. Campinas : IFCH-Unicamp, 1992.

SAHLINS, Marshall. Cultura e razão prática. Rio de Janeiro : Zahar, 1979.

SANTOS, Boaventura de Sousa. Pela mão de Alice, o social e o político na pós-modernidade. Porto : Edições Afrontamento, 1994.

THIOLLENT, Michael. Crítica metodológica, investigação social e enquete operária. São Paulo : Polis, 1981.

THOMPSON, John B. Ideologia e cultura moderna. Petrópolis : Vozes, 1995. 